\section{Stent-Less Percutaneous Coronary Intervention of Calcified Nodule Causing Non-ST-Elevation Myocardial Infarction - Serial Optical Coherence Tomography Follow-up After Rotational Atherectomy Followed by Drug-Coated Balloon Angioplasty-}

Masaru Ishida, MD; Takenori Ishisone, MD;

Takumi Kimura, MD; Yoshihiro Morino, MD

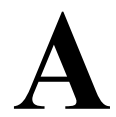
70-year-old woman was referred because of nonST-elevation myocardial infarction. Because urgent coronary angiography (CAG) showed ostial stenosis in the left circumflex artery (Figure A), we subsequently performed optical coherence tomography (OCT) imaging to assess lesion morphology; a calcified nodule $(\mathrm{CN})$ with white thrombus was found in the ostial stenosis (Figure B). To avoid crossover stenting, we decided to perform stentless percutaneous coronary intervention (PCI) for the ostial stenosis. After rotational atherectomy using a $1.5-\mathrm{mm}$ burr, predilatation by scoring balloon (NSE ADVANCE $3.0 \times 13 \mathrm{~mm}$, NIPRO, Osaka, Japan) was performed, followed by drug-coated balloon angioplasty (SeQuent please $3.0 \times 15 \mathrm{~mm}$, B Braun, Melsungen, Germany). Finally, good vessel expansion $\left(>4.9 \mathrm{~mm}^{2}\right)$ was obtained without major coronary dissection (Figure C,D; Supplementary Movie 1). After 5 months, CAG and OCT revealed no restenosis or development of CN (Figure E,F; Supplementary Movie 2).

It is reported that $\mathrm{CN}$ is related to poor clinical outcomes of stent implantation within several months, ${ }^{1}$ but the optimal strategy for $\mathrm{CN}$ has yet to be established. Although some case reports show the safety of stent-less PCI of stable $\mathrm{CN}$ lesions, this procedure for acute coronary syndrome (ACS)-related $\mathrm{CN}$ has never been reported. If sufficient

Received July 15, 2021; revised manuscript received July 26, 2021; accepted August 11, 2021; J-STAGE Advance Publication released online October 1, 2021 Time for primary review: 8 days

Division of Cardiology, Department of Internal Medicine, Iwate Medical University, Iwate, Japan

Mailing address: Masaru Ishida, MD, Division of Cardiology, Department of Internal Medicine, Iwate Medical University, 2-1-1 Idaidori, Yahaba-cho, Shiwa-gun, Iwate 020-3695, Japan. E-mail: maishida@ iwate-med.ac.jp

All rights are reserved to the Japanese Circulation Society. For permissions, please e-mail: cj@j-circ.or.jp ISSN-1346-9843

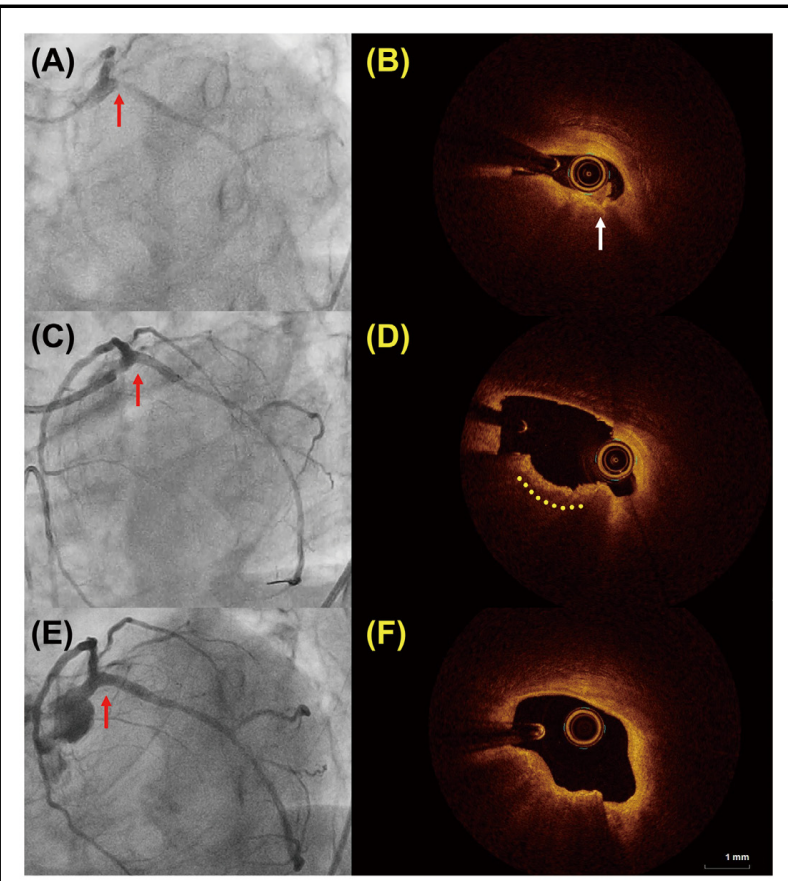

Figure. (A) Preprocedural coronary angiography (CAG) and (B) optical coherence tomography (OCT). (C) Post-procedural CAG and (D) OCT. (E) 5-month follow-up CAG and (F) OCT. Red arrows: culprit lesion. White arrow: calcified nodule. Dotted line: tissue ablated by rotational atherectomy.

luminal area can be obtained without major coronary dissection, stent-less PCI could be a therapeutic option even for $\mathrm{CN}$ causing ACS.

\section{Disclosures}

Y.M. is a member of Circulation Journal's Editorial Team.

\section{Reference}

1. Prati F, Gatto L, Fabbiocchi F, Vergallo R, Paoletti G, Ruscica G, et al. Clinical outcomes of calcified nodules detected by optical coherence tomography: A sub-analysis of the CLIMA study. EuroIntervention 2020; 16: 380-386.

\section{Supplementary Files}

Supplementary Movie 1. Post-PCI OCT image.

Supplementary Movie 2. Follow-up OCT image.

Please find supplementary file(s); http://dx.doi.org/10.1253/circj.CJ-21-0628 